\title{
Literatura Comparada e Estudos Clássicos: um diálogo interdisciplinar
}

Thiago de Souza Bittencourt Rodrigues

Universidade Federal de Minas Gerais thiagosbittencourt@yahoo.com.br

ABSTRACT: The aim of such investigation is to discuss, firstly, the issue of the "Greek miracle" in the light of an interdisciplinary dialogue between Comparative Literature and Classical Studies; secondly, to establish, from such discussion, its role in the process of the constitution of the "western tradition".

KEYWORDS: literary studies; classical studies; comparative literature; "Greek miracle".

O propósito dessa investigação é discutir, em primeiro lugar, o problema do "milagre grego" à luz de um diálogo entre a Literatura Comparada e os Estudos Clássicos; em segundo lugar, estabelecer, a partir dessa discussão, seu papel no processo de constituição da noção de "tradição ocidental". Assim, para introduzir o assunto e contextualizá-lo, será necessário precisar melhor o sentido de "tradição", bem como tentar caracterizar as transformações dessa "tradição" durante a passagem do século XIX para o XX, período no qual os Estados Nacionais ou Estados Nações se formaram, a partir de um esforço sintetizador das identidades nacionais. Depois de introduzido o quadro histórico sobre o qual o problema se instaura, será necessário explicitar as perspectivas teóricas que se pretende comparar, vale dizer, a Literatura Comparada e os Estudos Clássicos, apontando suas continuidades e esmiuçando suas rupturas, para só então avançar ao cerne da investigação, qual seja, uma reflexão sobre a questão do chamado "milagre grego" e as consequências dessa corrente teórica sobre a interpretação do papel da "tradição clássica" - compreenda-se aqui, por essa expressão, o legado das civilizações grega e romana -, sobre o estabelecimento da "tradição 
ocidental", 1 cuja "crise" põe fim ao período Moderno e dá início ao período que, segundo Stuart Hall, chama-se Pós-Modernidade. ${ }^{2}$

Desde o século XIX, em função de uma grande expansão dos meios de comunicação; do desenvolvimento tecnológico; do atrelamento da organização social à esfera estrita da economia do livre mercado, as diferentes sociedades "ocidentais" vinham experimentando uma transformação profunda e progressiva, não apenas de seus modelos políticos, fronteiras geográficas ou relações comerciais, mas de suas tradições culturais, religiosas, filosóficas, científicas e estéticas. Em suma, de seus valores.

No plano geopolítico, o século XIX assistiu a um novo processo de colonização, por parte dos Estados Nacionais europeus, que culminou com a partilha da África e da Ásia, apontando para uma nova expansão de seus modelos de pensamento e comportamentos em escala global; no plano econômico, o modelo capitalista se desenvolveu e definiu blocos hegemônicos de poder e classes sociais; a invenção do rádio, do telefone, a difusão da imprensa são fatores que, sem dúvida alguma, desempenharam um importante papel nessa transformação, diminuindo distâncias e rompendo fronteiras. Assim, o século XIX preparou uma "separação", uma "transformação" que caracterizou o século seguinte. Os filósofos contemporâneos, em geral, compreendem-na nos termos de uma "crise" - uma "crise" da Modernidade e de seus paradigmas cognitivos, de sua noção de "sujeito" e "racionalidade" - e consideram-na uma importante, senão a mais importante, característica da contemporaneidade.

A cultura ocidental ou "tradição" ocidental, enraizada no cultivo dos gregos e latinos, seus hábitos e tradições, experimentará uma ruptura radical, que segundo G. Bornheim, em "Conceito de Tradição", ${ }^{3}$ é evidenciada com a falência das verdades universais e metafísicas, preconizada por Nietzsche. Em lugar da esterilidade ontológica

\footnotetext{
${ }^{1}$ Vale lembrar que a oposição entre Ocidente e Oriente começou a ganhar contornos históricos mais precisos apenas com a divisão oficial do Império Romano entre os filhos de Teodósio I, após sua morte em 395 d.C., dando origem aos chamados Império romano do Ocidente e Império romano do Oriente (cf. Gibbon, E. Declínio e queda do Império Romano. Tradução de José Paulo Paes. São Paulo: Companhia das Letras, 2005, p. 414; p. 466-477); donde provém a oposição entre as noções geográficas "ocidental" e "oriental", que a princípio servem apenas para indicar as direções do pôr (occidens, -entis) e do nascer (oriens, -entis) do sol.

${ }^{2}$ Cf. Hall, S. A identidade cultural na Pós-Modernidade. Tradução de Tomaz T. da Silva e Guacira L. Louro. Rio de Janeiro: DP\&A, 1998, p. 23-46.

${ }^{3}$ Cf. Bornheim, G. A. O conceito de tradição. In: contradição. Rio de Janeiro: Zahar, 1987, p. 15-29. (org.) Cultura brasileira. Tradição, 
do princípio de identidade, sobrepor-se-á uma dialética que considere o sentido histórico e dinâmico desse novo "espírito de época" (Zeitgeist) e, então, o conceito, porta-voz da identidade, ver-se-á também, de uma vez por todas, esvaziado e reduzido a uma espécie de metáfora sem vida.

Ainda no mesmo ensaio, Bornheim avalia ${ }^{4}$ a trajetória do conceito de "tradição" à luz das críticas e perspectivas lançadas por F. Nietzsche (1844-1900) sobre a cultura ocidental e aponta para a oposição entre "tradição" e "ruptura" como constitutiva da própria cultura. Em outras palavras, caracteriza a contemporaneidade a partir da "crise" da noção de "tradição", isto é, da experiência da "ruptura", apontando, alhures, para o niilismo como essência da "tradição". Nesse sentido, o esvaziamento do conceito se torna ponto de partida para a necessidade de pensar o próprio estatuto do conhecimento, que, não mais sustentado pela universalidade oferecida pela identidade, viu-se obrigado a admitir em sua constituição uma medida de perspectivismo e quem sabe de ficcionalidade.

No campo da filosofia, foi a partir de Hegel que se estabeleceu mais explicitamente uma doutrina segundo a qual, tanto a realidade quanto o conhecimento são necessariamente históricos. O pensamento de Hegel, no entanto, compreende não uma história singular dos eventos, mas uma história absoluta, a qual abarca a própria história do Homem e na qual os acontecimentos desenvolvem-se em função das experiências do "Absoluto". Dentro desse contexto, o filósofo parece estabelecer uma relação de equivalência entre "tradição" e "história", que parece extrapolar para uma equivalência entre "tradição" e "cultura", muito difundida e muito criticada na história da Filosofia. ${ }^{5}$

No fundo, esses elementos históricos, filosóficos e culturais nos permitem estabelecer um contexto a partir do qual se possa discutir comparativamente.

Para retomar o ponto inicial da reflexão, o artigo de Bornheim, sobre o estabelecimento da "tradição" europeia ou ocidental, Nietzsche cunhou termos com os quais a "crise da tradição" passou a ser compreendida e discutida. ${ }^{6}$ De uma maneira

\footnotetext{
${ }^{4}$ Cf. Bornheim, op. cit., p. 16 ss.

${ }^{5}$ No que se refere à relação entre "tradição" e "cultura", cf. Bosi [Cultura como tradição. In: Bornheim, G. (org.). Cultura brasileira. Tradição, contradição. Rio de Janeiro: Zahar, 1987, p. 31-58]; quanto a um panorama da tradição filosófica sobre as questões relativas às noções de "cultura", "história" e "ruptura", cf. Pessanha [Cultura como ruptura. In: Bornheim, G. (org.). Cultura brasileira. Tradição, contradição. Rio de Janeiro: Zahar, 1987, p. 77ss.].

${ }^{6}$ Penso aqui na importância do perspectivismo genealógico e na crítica ao "sujeito" kantiano, elaborados por Nietzsche ao longo de sua fragmentária obra, e consequentemente, suas influências sobre as teorias
} 
geral, toda a obra do filósofo e filólogo alemão é dedicada à investigação do estabelecimento da concepção de "tradição ocidental" e dos motivos morais de sua derrocada, que chamou de niilismo. Segundo Nietzsche, no parágrafo oito de um texto chamado "Sobre o Niilismo", o conceito de niilismo é uma espécie de instinto de rebanho, uma crença na ausência de valor, que tem como causa outra crença, uma crença nas categorias da razão e na capacidade do "conceito" em dizer o "real". 7 Em última instância, o niilismo reside, por um lado, na falência da noção de Absoluto, considerado, até então, o valor mais elevado e, por outro, na incapacidade ou falta de potência da vontade em estabelecer novos valores, preferindo nada querer a querer $o$ nada.

Como se pode perceber em um trecho do Humano demasiado humano, Nietzsche sintetiza sua posição: ${ }^{8}$

(...) a teologia inteira está edificada sobre o falar-se do homem dos últimos quatro milênios como de um eterno, em direção ao qual todas as coisas do mundo desde seu início tenderiam naturalmente. Mas tudo veio a ser; não há fatos eternos: assim como não há verdades absolutas. Portanto, o filosofar histórico é necessário de agora em diante e, com ele, a virtude da modéstia (I, 1. §2).

A relação entre "tradição" e valores é para Nietzsche o ponto nevrálgico de toda discussão filosófica sobre a verdade e o niilismo. O problema pode ser formulado da seguinte maneira: se não há verdades absolutas sobre as quais nos apoiarmos para extrair certeza e segurança é porque não existe verdade nenhuma. Eis o equívoco da perspectiva metafísica transcendental: crer que a ausência de valores, dada a inexistência de um valor absoluto, é o único valor possível. ${ }^{9}$

literárias, sobre a filosofia e sobre a sociologia do século XX, em especial, sobre as perspectivas PósEstruturalistas como as de Foucault (A verdade e as formas jurídicas. Tradução de Roberto C. de Melo Machado e Eduardo J. de Moraes. Rio de Janeiro: PUC-RS, 2001, p. 12 ss.) e Deleuze (Nietzsche e a filosofia. Tradução de Edmundo Fernandes Dias e Ruth J. Dias. Rio de Janeiro: Ed. Rio, p. 3-4/ Nietzsche. Tradução de Alberto Campos. Lisboa: Edições 70, 1994).

${ }^{7}$ Cf. Nietzsche, F. W. Genealogia da Moral. Tradução de Paulo César de Souza. São Paulo: Companhia das Letras, 1998, p. 380.

${ }^{8}$ Cf. Nietzsche, F. W. Humano, demasiado humano. Tradução de Paulo César de Souza. São Paulo: Companhia das Letras, 2005.

9 Para uma apreciação mais pontual a respeito da inversão de valores seria necessário que nos remetêssemos à Genealogia da moral (cf. Nietzsche, op. cit., 1998), em especial a segunda e a terceira dissertações, acerca dos ideais ascéticos. Entretanto, isso fugiria à necessidade do objetivo aqui proposto, ficando, portanto, apenas como indicação bibliográfica. 


\section{nuntius antiquus}

Em última instância é uma perspectiva que se nega como tal e, por isso, tende a não reconhecer sua própria historicidade. Uma atitude que, para dizer o mínimo, tem consequências funestas no Ocidente.

Do ponto de vista político, os conflitos advindos desse "relativismo" contribuíram em muito para a alienação do homo faber, ${ }^{10}$ esse homem contemporâneo absorvido pelo trabalho (fabricação) e pelo consumo; além disso, possibilitaram, no mais das vezes, a ascensão de ditadores, tanto na Europa como na América Latina, em função de uma espécie de sentimento de inferioridade entre "colônia" e "metrópole", entre "governado" e "governante", que contamina a cultura ocidental de uma maneira geral, tanto mais quanto mais abaixo da linha do Equador ela se encontra. E pelas mesmas razões esses conflitos permitiram uma ditadura grosseira do mercado e da mercadoria sobre a cultura e a arte no mundo globalizado.

Essa discussão toma, no campo da Estética, proporções bastante acentuadas, uma vez que o lugar da cultura e da arte na "era da reprodutibilidade técnica" é estabelecido em função de uma demanda de mercado, que desconsidera os interesses locais e individuais, priorizando uma padronização forçada, que atende apenas aos interesses do próprio mercado, isto é, não agrega nada à sociedade, nem ao indivíduo que as consome, mas apenas acentua o processo alienador a que já se submetem as massas e a cultura. Na esfera da indústria cultural e da cultura de massa, o homem e a obra de arte são reduzidos à condição de artesanato, entretenimento e/ ou simples recurso, um mero meio. ${ }^{11}$ Para além do pessimismo exacerbado dos frankfurtianos, não se pode deixar de notar uma relação estreita entre mercadoria, mercado e "menoridade" do homem, que já se faz perceber latente em muitas de nossas redes de fomento à pesquisa e instituições de ensino, espalhada pelas mais diversas áreas do conhecimento e perspectivas teóricas.

No campo dos Estudos Literários, esse processo de "desencantamento", que certamente poderíamos também chamar de "desconstrução" da "tradição" ou

${ }^{10}$ A expressão latina homo faber foi cunhada em 1958 por Hannah Arendt (A condição humana), para descrever o homem destituído de sua condição e tornado mero instrumento e, portanto, limitado pelo uso instrumental da razão, algo que Kant, em seu opúsculo "Resposta à pergunta: que é esclarecimento?" (In: . (org.) Textos seletos. Tradução de Floriano S. Fernandes. Petrópolis: Vozes, 1974, p. 100-

117), havia chamado de "menoridade".

${ }^{11}$ Para Adorno e Horkheimer (A indústria cultural: o esclarecimento como mistificação das massas. In: . (org.) Dialética do esclarecimento. Tradução de Guido A. de Almeida. Rio de Janeiro:

Zahar, 1985, p. 99-138), a "crise" da modernidade, compreendida como consequência necessária do esclarecimento e da perda da condição humana, desencadeia um desencantamento do mundo que se reflete nitidamente na indústria cultural. 
simplesmente de "crise", faz-se sentir primeiramente nas críticas que as poéticas do romantismo alemão lançaram sobre as poéticas neoclássicas do século XVIII, em especial àquilo que nelas se refere à teoria dos gêneros. O Romantismo do século XIX está em desacordo com a concepção preceptista da pureza dos gêneros literários; ao contrário, ele atribui movimento e vida aos gêneros, que nascem, vivem e podem morrer ou se transformar. Enquanto os preceptistas neoclássicos restringiam a delimitação da "literatura" ao âmbito estrito dos três gêneros considerados essenciais desde Aristóteles e Horácio - a épica, a lírica e o drama - os românticos apontavam para a inexistência de gêneros essenciais, preconizando uma apologia do hibridismo. ${ }^{12}$ A crítica romântica tem este mérito: atribuir à Literatura uma história, uma organicidade viva, advinda da busca pelo que lhe é próprio.

Esse mesmo movimento serviu de ensejo ao recolhimento no final do qual os EstadosNações europeus prorromperam sobre a terra. Nesse sentido, a "crise" da modernidade ou "crise" da "tradição" caracteriza o contexto contemporâneo de maneira visceral. Enfim, depois dessa extensa digressão, com a qual espero ter contextualizado o século XIX e a passagem para o século XX, passo agora a explicitar, a partir desse contexto, a relação entre dois campos dos estudos literários, a saber, Literatura Comparada e Estudos Clássicos.

Mesmo que, do ponto de vista institucional, a Literatura Comparada e os Estudos Clássicos tenham-se estabelecido, enquanto disciplinas acadêmicas, apenas no século XIX, sendo por isso, muito recentes, ainda assim, constituem dois eixos teóricos relevantes dos estudos literários, pois o objeto sobre o qual se debruçam é de algum modo o mesmo, isto é, a relação entre memória e tradição. Eles representam, assim, polos complementares de um mesmo impulso civilizacional. Como ficou dito acima, a "tradição" é ela mesma parte de um ciclo incessante, nos termos de Bornheim, composto de rupturas e estabelecimentos, ao menos é o que espero demonstrar aqui.

A partir de uma aproximação entre esses dois eixos, os Estudos Clássicos, debruçados sobre as origens da tradição e sua transmissão, e a Literatura Comparada, atenta à ruptura e à fragmentação dessa tradição, buscarei analisar o problema do "milagre grego" em uma perspectiva comparatista. Mas, antes, cabe ressaltar de maneira

12 O hibridismo é o resultado de uma transculturação inevitável e, ao mesmo tempo é condição de possibilidade de uma voz latino-americana, mestiça, regional e, por isso mesmo, objeto de interesse dos atuais estudos em Literatura Comparada, como os trabalhos de A. Rama, N. G. Canclini e A. Moreiras. 
mais precisa a relação entre o estabelecimento da "tradição" e a "memória", para que se possa finalmente retomar a caracterização dos eixos teóricos e somente a partir daí atacar o problema central.

O papel desempenhado pela "memória" no Ocidente logrou abarcar sentidos muito diversificados, entretanto, de uma maneira geral, se refere a algo que foi recolhido, guardado pelas gerações e se estabeleceu como uma espécie de arquivo cultural humano. A própria ideia de educação repousa na transmissão da "memória" como algo que se cultiva, donde se percebe que a relação entre "memória" e cultura, portanto, entre "memória" e "tradição", estabelece, por um lado, o material cultural a ser transmitido e, por outro, o resultado dessa transmissão. Nesse sentido, a "memória" representa a principal fonte da "tradição".

Ricardo Piglia, em um artigo no qual discute justamente as relações entre "memória e tradição", embora limite a discussão ao contexto da tradição literária argentina, esforça-se para demonstrar a dimensão estrangeira no estabelecimento da memória, dizendo: “a identidade de uma cultura se constrói na tensão utópica entre o que não é de ninguém e anônimo e o uso privado da linguagem, o que convencionamos chamar de literatura", ${ }^{13}$ e reafirma adiante: "a identidade de uma cultura se define pelo modo como usa a tradição estrangeira". ${ }^{14}$ A novidade da perspectiva de Piglia sobre a relação entre a "memória e a tradição" se refere ao apontamento da dimensão coletiva da palavra, na qual o passado, guardado pela memória, pode filtrar o presente por uma ótica que permite revisitá-lo. "Há que se ter um olho posto na inteligência europeia e outro posto nas entranhas da pátria". ${ }^{15}$ Daí, a importância de se estabelecer um diálogo entre Literatura Comparada e Estudos Clássicos. Em última instância, os Estudos Clássicos focalizam suas investigações sobre as literaturas e culturas antigas, fontes da "tradição", enquanto a Literatura Comparada investiga as consequências sofridas pela literatura contemporânea em meio à "crise" dessa "tradição" estabelecida.

A Literatura Comparada se debruça, primeiramente, sobre a temática da formação da identidade cultural dos Estados Nacionais e nasce apenas no século XIX, ${ }^{16}$ como observam P. Brunel, C. Pichois e A. M. Rousseau: ${ }^{17}$

\footnotetext{
${ }^{13}$ Cf. Piglia R. Memoria y Tradición. In: Anais $2^{\circ}$ Congresso Abralic: literatura e memória cultural. Belo Horizonte, 1991, p. 61.

${ }^{14}$ Cf. Piglia, op. cit., p. 64.

${ }^{15}$ Cf. Piglia, op. cit., p. 61.

${ }^{16}$ As perspectivas e metodologias comparativistas começam a surgir no final do século XIX, início do século XX, em especial, no campo das ciências da natureza, como uma espécie de antídoto contra o
} 
Foi preciso sobretudo que o século dos nacionalismos, exaltando o sentido da história, as tradições, o folclore, e chamando à vida literaturas agonizantes, obrigasse cada povo, cada grupo étnico, a tomar consciência de sua unicidade no quadro da humana comunidade.

Em seguida, distancia-se da esfera estrita das literaturas nacionais e amplia sua perspectiva em função das literaturas transnacionais, isto é, das literaturas de fronteira, sejam elas nacionais, étnicas ou genéricas. Para M.-F. Guyard, "a Literatura Comparada é a história das relações literárias internacionais"; “o comparatista se encontra nas fronteiras, linguísticas ou nacionais"18 e se "ocupa, em geral, de personalidades que parecem ter a vocação para intérpretes de seu país junto a um outro, ou mais frequentemente, de uma cultura estrangeira junto à de sua pátria". ${ }^{19}$ R. Wellek acusa uma falência desse primeiro paradigma de Literatura Comparada, alegando que "o sinal mais sério de estado precário de nossas pesquisas reside no fato de que ainda não se foi capaz de estabelecer um objeto de estudo distinto e uma metodologia específica". ${ }^{20}$ Ele acusa Baldenspenger, Van Tieghem, Carré e Guyard de falharem nessa tarefa, sobrecarregando a Literatura Comparada com metodologia obsoletas, deixando de lado o fato de que a "tradição ocidental" é composta de uma rede de inúmeras interrelações e não pode ser reduzida ao estudo do comércio exterior entre literaturas. ${ }^{21}$

Para Wellek e Warren, “o grande argumento a favor da Literatura Comparada é a evidente falsidade da ideia de uma literatura nacional fechada em si mesma”, por isso não se pode negar que a literatura ocidental tenha uma unidade, um todo: ${ }^{22}$

Não podemos duvidar da continuidade entre a literatura grecoromana, o mundo medieval ocidental e as principais literaturas modernas, e, sem minimizar a importância das influências orientais,

positivismo (cf. Carvalhal, T. F. Literatura comparada. São Paulo: Ática, 2006, p. 8). Mas ainda no século XIX podemos perceber uma difusão dessa perspectiva para outros campos do conhecimento: arqueologia comparada, mitologia comparada, história comparada das religiões, literatura comparada etc.

17 Cf. Brunel, P.; Pichois, C.; Rousseau, A. M. Que é Literatura Comparada? Tradução de Célia Berrettini. São Paulo: Perspectiva, 1995, p. 3.

${ }^{18}$ Cf. Guyard, M. F. Objeto e método da Literatura Comparada. In: Coutinho, E. F.; Carvalhal, T. F. (org.). Literatura comparada: textos fundadores. Rio de Janeiro: Rocco, 1994, p. 97.

${ }^{19}$ Cf. Guyard, op. cit., p. 101.

${ }^{20}$ Cf. Wellek, R. A crise da Literatura Comparada. In: Coutinho, E. F.; Carvalhal, T. F. (org.). Literatura comparada: textos fundadores. Tradução de Maria L. R. Coutinho. Rio de Janeiro: Rocco, 1994, p. 108.

${ }^{21}$ Cf. Wellek, op. cit., p. 109.

${ }^{22}$ Cf. Warren, A.; Wellek, R. Literatura Geral, literatura comparada e literatura nacional. In: (org.) Teoria da literatura e metodologia dos estudos literários. Tradução de Luis C. Borges. São Paulo: Martins Fontes, 2003, p. 51. 
especialmente a Bíblia, devemos reconhecer uma unidade íntima, que inclui toda a Europa, a Rússia, os Estados Unidos e as literaturas latino-americanas.

Como se pode perceber, não há um único sentido, mas ao contrário existem diversos sentidos para Literatura Comparada. Há pelo menos três significados dominantes de Literatura Comparada, segundo Wellek e Warren: o estudo da literatura oral e do folclore; o estudo das relações entre duas ou mais literaturas; e o estudo da literatura em sua totalidade ou "literatura universal". ${ }^{23}$

O primeiro significado, isto é, Literatura Comparada como estudo da literatura oral e do folclore, remete-nos ao estudo das narrativas populares e seu desenvolvimento, embora não seja simples delimitar o escopo comparatista no estudo da oralidade. $O$ exemplo da fábula pode nos ajudar a compreender este significado, afinal, a fábula, desde seus primórdios, pertence ao conjunto das literaturas de cunho oral, sendo, assim, capaz de atravessar fronteiras culturais, nacionais, étnicas, assimilando e sendo assimilada por diversas culturas, constituindo uma espécie de arcabouço de sabedoria prático-moral a partir da qual traços significativos da memória cultural do ocidente se estabeleceram. $^{24}$

O próprio Piglia, no artigo supracitado, diz que a relação entre "memória" e “tradição" pode ser vista como um "modo de tratar a literatura já escrita com a mesma lógica com que tratamos a linguagem: tudo é de todos, a palavra é coletiva, anônima". ${ }^{25}$ Nesse sentido, poderíamos pensar que a fábula é o gênero comparativo por excelência, regional, na medida em que assimila e sintetiza a cultura a partir do que lhe é próprio, nacional, sem, no entanto, deixar de ser extra-nacional, devido à mesma capacidade de dialogar dialeticamente com a diferença. Embora fosse necessário demonstrar textualmente este itinerário de transmissão da fábula, isso exacerbaria as dimensões da investigação aqui proposta, porque desviaria a investigação desnecessariamente do objeto, essa demonstração será feita em outra oportunidade. Por enquanto, retomemos a caracterização dos significados dominantes de Literatura Comparada.

\footnotetext{
${ }^{23}$ Cf. Warren; Wellek, op. cit., p. 47-50.

${ }^{24}$ A origem da fábula é híbrida. Embora Esopo (escritor grego do século VII-VI) tenha sido reconhecido pela tradição ocidental como inventor (euretés) desse gênero literário, é forçoso reconhecer sua presença entre egípcios, indianos, assírios e judeus (cf. Chambry, E. Notice sur Ésope. In: Ésope. Fables. Paris: Les Belles Lettres, 1985, p. IX-XXVII).

${ }^{25}$ Cf. Piglia, op. cit., p. 60.
} 
O segundo significado - lembrando: Literatura Comparada como estudo das relações entre duas ou mais literaturas - nos aproxima do sentido estabelecido pelos comparatistas franceses, cujas questões relevantes são a reputação e a penetração, a influência e a fama. Segundo nos alerta Wellek, “obras de arte, no entanto, não são simples somatórios de fontes e influências, são conjuntos em que a matéria-prima vinda de outro lugar deixa de ser matéria inerte e passa a ser assimilada numa nova estrutura". ${ }^{26}$ Por isso, ele recusa esse segundo significado, apontando-o como um sintoma da "crise" na Literatura Comparada.

O terceiro significado - vale lembrar: Literatura Comparada como "literatura universal" (Weltiteratur), ou da literatura em sua totalidade - nasceu do termo cunhado por Goethe, como mostra H. Achugar, ${ }^{27}$ para designar uma "literatura mundial" em oposição a uma "literatura nacional"; depois como "literatura cosmopolita", em função de sua relação com o estabelecimento da "nova ordem mundial", estabelecida pela união internacional entre franceses, ingleses e alemães; em seguida, Marx e Engels, no Manifesto Comunista, a redefinem como fator de globalização, isto é, como instrumento ideológico utilizado pela burguesia para alienar o proletariado em benefício dos interesses do mercado mundial. ${ }^{28}$

Em resumo, a Literatura Comparada ocupou-se, em primeiro lugar, do estabelecimento dos Estados Nacionais, que foram buscar na Antiguidade grega e latina o berço e a origem de sua civilização e de sua "tradição"; em seguida rompeu os laços e emancipou-se da "tradição", tornando o próprio colapso, a ruptura, a "crise" da "tradição", bem como tudo o que ela havia representado, seu objeto. Exageros à parte, é preciso lembrar que mesmo entre os gregos antigos a tomada de consciência de si fezse, ela própria, por meio de uma tradição literária híbrida. Nesse sentido, uma retomada da tradição clássica pelo viés comparatista permitiria investigar mais uma vez as origens da tradição literária ocidental de maneira menos afetada pela "originalidade", noção que repercute no repertório dos Estudos Clássicos desde sua origem, como pretendo evidenciar com o problema do "milagre grego".

Oriundos dos estudos de Filologia, os Estudos Clássicos nasceram da ampliação da discussão sobre a Antiguidade, agregando à discussão sobre a transmissão da

\footnotetext{
${ }^{26}$ Cf. Wellek, op. cit., p. 111.

${ }^{27}$ Cf. Achugar, H. Weltliteratur ou cosmopolitismo, globalização, "literatura mundial" e outras metáforas problemáticas. In: ___ (org.) Planetas sem boca, escritos efêmeros sobre arte, cultura e literatura. Tradução de Lyslei Nascimento. Belo Horizonte: UFMG, 2006, p. 67-69.

${ }^{28}$ Cf. Achugar, op. cit., p. 70. 


\section{nuntius antiquus}

tradição clássica greco-romana, elementos comparados de literatura, filosofia, arqueologia, paleografia. ${ }^{29}$ Embora não seja difícil pensar em uma unidade mínima, estabelecida pelo contato entre os povos mediterrâneos, talvez fosse necessário traçar estratégias metodológicas mais precisas do que as que até então haviam sido utilizadas; caso contrário, as comparações não passariam de simples conjecturas, meros devaneios, misto de diletantismo e excesso de erudição.

Os Estudos Clássicos, embebidos pelo espírito comparatista, trouxeram um novo fôlego para o estudo das civilizações antigas, permitindo-lhe a abertura de um diálogo interdisciplinar simbiótico. Segundo essa perspectiva, tornou-se necessário pensar os gregos a partir dos não gregos, isto é, a partir das fronteiras. ${ }^{30}$ Assim, não seria absurdo pensar que trânsito e empréstimos sempre foram um elemento característico de todas as civilizações ou épocas históricas.

As semelhanças entre a Literatura Comparada e os Estudos Clássicos não se esgotam por aí: tanto uma como a outra necessitam de um amplo e diversificado domínio de suas fontes de pesquisa. Desde seus primórdios, o "equipamento" do estudioso de Estudos Clássicos e do Comparatista se caracteriza pelo excesso de erudição instrumental. Nesse sentido, o comparatista e o filólogo têm em comum a perspectiva genealógica, buscando decifrar a partir das camadas históricas certas semelhanças de família; o comparatista nega uma tradição unívoca e estabelece o diálogo entre tradições, o filólogo colaciona manuscritos; ambos procurando estabelecer uma tradução que possibilite um diálogo entre modernos e antigos, antes que o peso homogeneizante do vir a ser das coisas sobreponha-se sobre a multiplicidade das vozes.

Até meados do século XIX da era cristã, os estudos sobre as tradições literárias e filosóficas gregas desconsideravam a importância do trânsito entre as diversas civilizações que, desde o final do período neolítico, desenvolveram-se nas margens do Mediterrâneo. Esse quadro parece se alterar a partir de 1950, quando novas descobertas arqueológicas e linguísticas proporcionaram uma abertura na perspectiva de

\footnotetext{
${ }^{29}$ Cf. Righi, G. Historia de la filología clásica. Traducción de J. M. García de la Mora. Barcelona: Labor, 1969.

${ }^{30}$ Veja-se o "quadro histórico" de Vernant (As origens do pensamento grego. Tradução de Ísis B. B. da Fonseca. Rio de Janeiro: Bertrand Brasil, 1998, p. 15-20); a "Invenção do bárbaro e inventário do mundo", em Hartog (Memória de Ulisses: narrativas sobre a fronteira na Grécia antiga. Tradução de Jacyntho Lins Brandão. Belo Horizonte: UFMG, 2004, p. 93-101); e Momigliano (Os limites da helenização. Tradução de Cláudia Martinelli Gama. Rio de Janeiro: Zahar, 1991).
} 
investigação desses estudos. Os trabalhos de M. Ventris e J. Chadwick resultaram, em 1952, na decifração do Linear B. Muito embora as placas de barro não contenham muito além de informações sobre a administração dos palácios micênicos e algumas poucas informações religiosas, como o nome de deuses, por exemplo, elas forneceram indícios suficientes para reavaliar a "originalidade" do chamado "milagre grego". 31

As primeiras críticas à pretensa "originalidade" dos gregos foram desenvolvidas na escola de Cambridge, oriundas dos estudos de arqueologia comparada. Dentre esses estudos, um merece especial atenção, uma obra póstuma de Cornford, editada e prefaciada por Guthrie, o Principium Sapientiae: as origens do pensamento filosófico grego, que contém a primeira comparação de fôlego entre a literatura grega e a literatura babilônica, no sentido de apontar aproximações entre elas. ${ }^{32}$ Segundo o próprio Cornford: $:^{33}$

Apesar de algumas discrepâncias, talvez seja agora suficientemente claro que o mito cosmogônico de Hesíodo deriva, em última análise, do mito babilônico. As discrepâncias são menos marcantes do que as coincidências, e são em menos número do que seria de esperar.

Além disso, as escavações na Anatólia, no Crescente Fértil, no Oronte, na estrada dos peregrinos e mercadores que ligava a Mesopotâmia ao mar, em Cnossos, Pilos e Micenas, a decifração das placas de argila escritas em cuneiforme trazidas à luz em Mari, Alalakh, Ugarit e Hattusa; a constatação de uma tradição literária hitita

${ }^{31}$ Essa é a expressão utilizada para marcar uma determinada perspectiva de leitura sobre as origens da filosofia grega que supõe uma completa originalidade por parte dos gregos e se opõe à ideia de uma origem oriental. O livro primeiro das Vidas e doutrinas dos filósofos ilustres, de Diógenes Laércio, parece contribuir com tal perspectiva: nele o doxógrafo rebate a possibilidade da invenção bárbara da filosofia e reafirma sua origem helênica $(\$ 4)$. Mas entre todas as obras que fundamentam a perspectiva do "milagre grego", a mais substancial ainda é a Aurora da filosofia grega, de J. Burnet, publicada pela primeira vez em 1892 e depois reeditada e traduzida inúmeras vezes. Burnet compreende a perspectiva orientalista como uma espécie de preconceito contra a originalidade grega (Burnet, J. A aurora da filosofia grega. Tradução de Vera Ribeiro. Rio de Janeiro: PUC-RIO, 2006, p. 31), tendo afirmado que a Jônia, antes da chegada dos aqueus, era mesmo uma "região sem passado" (op. cit., p. 29) e, por isso, a pretensa origem oriental da filosofia caía por terra. Segundo sugere Burnet, o caráter científico que impulsionou a filosofia em seus primórdios foi favorecido pela inexistência de uma classe sacerdotal entre os aqueus, o que teria favorecido a "ascensão da ciência livre entre eles" (op. cit., p. 23). Embora admita em algumas passagens que os gregos possam ter recebido influências estrangeiras e, portanto, "devemos estar preparados para constatar que os primeiros gregos dos tempos históricos a tentar compreender o mundo não estavam, de modo algum, na situação de homens que começavam a trilhar um caminho até então inexplorado" (op. cit., p. 22), Burnet não reconhece nenhuma dívida dos gregos no que se refere à invenção da filosofia, nem com os egípcios, nem com os babilônicos.

${ }^{32}$ Cornford compara o hino a Zeus nos poemas de Hesíodo ao hino a Marduk, o deus babilônico da Tempestade.

${ }^{33}$ Cornford, F.-M. Principium Sapientiae. As origens do pensamento filosófico grego. Tradução de Maria Manuela R. dos Santos. Lisboa: Calouste Gulbenkian, 1975, p. 407. 


\section{nuntius antiquus}

riquíssima, ${ }^{34}$ todos esses acontecimentos modificaram nossa visão sobre o chamado Oriente Próximo e suas relações com o mundo egeu, suas tradições e sua cultura.

A reelaboração do quadro histórico, observada no campo da arqueologia comparada, ganhou novos impulsos a partir dos dados sociológicos e antropológicos introduzidos pelos estudos de Louis Gernet, segundo o qual, durante muito tempo acreditou-se numa criação ex nihilo da filosofia, "mas descobertas recentes fizeram constatar que a Grécia clássica possuía um longo passado".35

Nesse sentido, o acompanham os estudos da chamada Escola de Paris, em especial os trabalhos de J.-P. Vernant, sobre as relações entre o mito e os diversos aspectos da cultura grega. No início do primeiro capítulo de As origens do pensamento grego, Vernant ressalta que "no início do II milênio, o Mediterrâneo não marca ainda em suas duas margens uma separação entre o Oriente e o Ocidente". ${ }^{36}$ Segundo ele, "o mundo egeu e a península grega se ligam sem descontinuidade, como povoação e como cultura (...) com a Mesopotâmia e o Irã", 37 Além da cerâmica, a utilização do cavalo para fins bélicos sublinha essas afinidades e apresenta um tipo semelhante de organização social nas duas margens do Mediterrâneo, bem como uma rede de intercâmbios, contatos e comunicações já definidos desde o século XIV a.C., quando os micênicos substituíram os cretenses nas relações comercias com as cidades do Levante.

Ao lado dos estudos arqueológicos, sociológicos, antropológicos e linguísticos somaram-se estudos filosóficos e literários, que, conjugados em uma ótica comparatista, romperam com a ideia de "originalidade" tão marcante no campo dos estudos sobre literatura grega. Quando Albin Lesky publica sua monumental História da literatura grega, entre 1957 e 1958, a hipótese de uma relação mais estreita entre Ocidente e Oriente já havia sido estabelecida; ele próprio reconhece que, para "o povo grego como

\footnotetext{
${ }^{34}$ Para uma visão geral da cultura babilônica, cf. obras de Bottero [Bottero, J. et alii (org.). Cultura, pensamento e escrita. Tradução de Rosa de Maria Boaventura e Valter Lellis Siqueira. São Paulo: Ática, 1995/ La religion babylonienne. Paris: Presses Universitaires de France, 1952]; para uma visão mais específica sobre a literatura, cf. obras de Lambert (Babylonian wisdow literature. Oxford: Clarendon Press, 1960/ Textos literários hetitas, de autoria anônima, cuja tradução, introdução e notas foi cuidada por A. Bernabe (1979)]; para estabelecer uma relação entre os textos hititas e os textos gregos, cf. obras de West (The east face of Helicon: west Asiatic elements in Greek poetry and myth. Oxford/ New York: Clarendon Press, 1997); de Walcot (Hesiod and the near east. Cardiff: University of Wales Press, 1966); e de Adrados ("Sobre los géneros literarios en la literatura griega". In. 1616, Madrid, p. 159-172, 1978).

${ }^{35}$ Cf. o ensaio de Gernet (Les origines de la philosophie In. Anthropologie de la Grèce antique. Paris: Flammarion, 2002, p. 240).

${ }^{36}$ Cf. Vernant, op. cit., p. 15.

${ }^{37}$ Cf. Vernant, op. cit., p. 15.
} 


\section{nuntius antiquus}

tal, também o seu mito é resultado duma combinação de elementos indoeuropeus e mediterrânicos". 38

Lesky não admite destituir os gregos de sua posição superior frente às demais culturas mediterrâneas, mas não deixa de reconhecer a importâncias de elementos orientais, em especial, na poesia de Hesíodo: "[n]a Teogonia encontramos uma tradição de procedência diversa, misturada"; ${ }^{39}$ e nas fábulas, talvez únicos remanescentes das narrativas populares, cuja "origem é também oriental". ${ }^{40}$ Com a descoberta e tradução dos poemas hititas, depois da década de 50 do século XX, uma nova luz foi lançada sobre a literatura grega. Ainda que Lesky não admita estabelecer uma comparação exata entre os poemas de Hesíodo e os mitos de soberania do Oriente Próximo - como o mito do reino celeste hurrita-hitita, cuja sucessão começa com Alalu, depois Anu e por fim Kumarbi; ou a canção de Ullikumi, ou o Enuma Elish babilônico -, ele deixa de mencioná-los para apresentar pontos de contato entre esses poemas e a Teogonia; em linhas gerais, sua linha principal de desenvolvimento se dá através das sucessivas alternâncias do poder até a ascensão e entronamento de Zeus. O que haveria de específico na Teogonia, segundo Lesky, reside no fato de que, diferentemente dos mitos sucessórios do Oriente Próximo, no poema de Hesíodo a narrativa converge para Zeus e o estabelecimento de uma ordem calcada na "justiça". ${ }^{41}$ Além de encerrar em seu núcleo temático uma narrativa de soberania, ainda que com nuances, a concepção dos deuses primordiais da cosmogonia hesiódica assemelha-se a certas concepções orientais; Cháos e Eros são exemplos disso, segundo Lesky. ${ }^{42}$

Ainda que não seja o caso de investigar o quanto de literatura hitita e mesopotâmica exista nos poemas de Hesíodo ou precisar a influência das fábulas egípcias e mesopotâmicas sobre as fábulas gregas atribuídas a Esopo, certas semelhanças não poderiam deixar de chamar a atenção. Não porque apontam para uma linha sucessória linear de fontes e influência, mas porque tais elementos evidenciam um

\footnotetext{
${ }^{38}$ Cf, Lesky, A. História da literatura grega. Tradução de Manuel Losa. Lisboa: Calouste Gulbenkian, 1995, p. 24.

${ }^{39}$ Cf. Lesky, op. cit., p. 118.

${ }^{40}$ Segundo J. Svembro, Lesky se insere no quadro das interpretações dualistas sobre a Teogonia, como W. Luther, W. Schmid, W. Jaeger, K. Latte, H. Fränkel, W. Kraus, que interpretam o poema de Hesíodo como porta-voz de algo que surge originalmente com os gregos, a "soberania do espírito" (cf. Hésiode: La vérité comme relation sociale. In: La parole et le marbre. Aux origines de La poétique grecque. Lund: Studentlitteratur, 1976, p. 48-49).

${ }^{41}$ Cf. Lesky, op. cit., p. 120.

${ }^{42}$ Cf. Lesky, op. cit., p. 121. 
grau de intertextualidade que não pode ser ignorado, uma vez que a intertextualidade é, ela mesma, indício de trânsito, de troca e, portanto, permite a comparação. ${ }^{43}$

Grosso modo, desde meados do século passado, em função de novas evidências textuais e arqueológicas, uma das mais difundidas interpretações sobre o surgimento da literatura e da filosofia entre gregos começou a ser questionada. A interpretação que ficou conhecida como o "milagre grego" surgiu no final do século XIX e consolidou-se com a publicação da obra Aurora da Filosofia, de John Burnet, em 1892, na qual o classicista de Oxford sustenta a "originalidade" dos gregos em relação a seus vizinhos no Mediterrâneo. O "milagre grego" fundamenta-se nessa "originalidade", que tornou os gregos conhecidos por sua arte e ciência, mas ao mesmo tempo consolidou uma série de equívocos; entretanto, muitas vezes esses equívocos forneceram as características daquilo que para nós tornou-se a tradição ocidental, isto é, a nossa "tradição".

Em seu Prefácio à terceira edição inglesa de A aurora da filosofia grega, John Burnet reafirma o objetivo principal de sua obra: "mostrar que algo novo - aquilo a que chamamos ciência - surgiu no mundo com os primeiros mestres jônicos e que eles foram os primeiros a apontar o caminho que a Europa tem seguido desde então". ${ }^{44}$ Para ele, a ciência só existiu nos povos que sofreram influência da Grécia; nesse sentido, egípcios e mesopotâmicos, ainda que anteriores, só chegaram a desenvolver algo como ciência a partir de seu contato com o gregos, sendo assim, aqueles é que seriam tributários destes. Burnet delimita as origens da filosofia grega dentro de uma perspectiva semelhante à lógica que submete a Colônia à Metrópole, fazendo daquela uma mera reprodutora das tradições da matriz. ${ }^{45}$

A tese central do argumento de Burnet repousa sobre a "originalidade" dos gregos em criar uma investigação sobre a realidade não sensorial que será conhecida

\footnotetext{
${ }^{43}$ Em um artigo intitulado "Perspectivas da Literatura Comparada no Brasil", Eneida M. Souza e Wander M. Miranda discutem a dependência cultural que, durante os primeiros anos nortearam os estudos comparatistas brasileiros, e apontam para um redirecionamento teórico, após a década de 70. Segundo eles, esse redirecionamento se deu em função da desestabilização da oposição binária do tipo centro/ periferia, a partir da retomada da noção de intertextualidade elaborada por Bakhtin e J. Kristeva, "ao desvincular o discurso literário de um caráter fechado e auto-suficiente" [Perspectivas da Literatura Comparada no Brasil. In: Carvalhal, T. F. (org.). Literatura Comparada no mundo: questões e métodos. Porto Alegre: L \& PM/ VITAE/ AILC, p. 41].

${ }^{44}$ Cf. Burnet, J. A aurora da filosofia grega. Tradução de Vera Ribeiro. Rio de Janeiro: PUC-RIO, 2006, p. 11.

${ }^{45}$ É curioso notar, no campo da Literatura Comparada, o esforço de Mignolo em estabelecer os conceitos de particular e universal para discutir o Eurocentrismo, isto é, o colonialismo com o qual a América Latina precisa romper, para ser capaz de deixar de lado o sentimento de inferioridade em sua produção intelectual (cf. Histórias locais/ projetos globais; colonialidade, saberes subalternos e pensamento liminar. Belo Horizonte: UFMG, 2003, p. 133-180).
} 


\section{nuntius antiquus}

como "ciência" ou "filosofia". Segundo o próprio Burnet, esse é o ponto vital de sua argumentação. Em última instância, ele termina por mitigar a importância do trânsito entre culturas em função de uma suposta superioridade dos gregos.

A perspectiva do "milagre grego" atribuiu ao advento da razão o status de "passagem" do mýthos para o lógos. A partir de então, o estatuto da linguagem receberia uma dupla caracterização que até hoje se discute: de um lado o discurso científico, articulado por meio do conceito e tendo como objetivo dizer a "verdade"; de outro, o discurso ficcional ou literário, de uma vez por todas destituído de caráter gnosiológico. Ora, este é um dos equívocos, para não dizer preconceitos, que ainda precisam ser enfrentados. Mas em primeiro lugar é necessário avaliar a noção de "originalidade" sobre a qual repousa a hipótese do "milagre".

Alguns anos depois da publicação do texto de Burnet, precisamente em 1912, a perspectiva do "milagre grego" experimentou seu primeiro abalo, com um estudo pioneiro intitulado From religion to philosophy: a study in the origins of western speculation, de F. M. Cornford, no qual o helenista de Cambridge faz uma apreciação do elemento religioso presente na constituição da especulação científica grega, questionando, assim, a "passagem" do mýthos para o lógos. Um segundo ataque viria anos mais tarde, quando, em 1952, foi publicada a obra póstuma de Cornford, chamada Principium Sapientia: as origens do pensamento filosófico grego, onde ele retoma as comparações de 1912, avança suas pesquisas e confronta comparativamente a literatura grega arcaica à literatura mesopotâmica, ambas de cunho didático e popular.

A via aberta pela perspectiva de Cornford levou a questionar a "originalidade" do "milagre grego", a partir do trânsito entre literaturas, que se revelou mais profundo e ramificado do que se imaginava na época de Burnet. Em última instância, ela põe em xeque as próprias fronteiras entre Ocidente e Oriente, ressaltando os hibridismos, a intertextualidade e a importância das narrativas populares na formação da identidade cultural dos povos. Desde então, o "milagre grego" tornou-se uma questão delicada,

sobre a qual ainda hoje restam dúvidas e incertezas. É aqui que a Literatura Comparada pode oferecer aos Estudos Clássicos sua maior contribuição: a interdisciplinaridade.

\section{Conclusão}

A interdisciplinaridade constitui, nesse sentido, uma posição intermediária, isto é, mediadora, característica de um procedimento crítico que se move entre dois ou mais 


\section{nuntius antiquus}

elementos. Para Luiz C. Lima, o comparatista é um agenciador do intercâmbio cultural. ${ }^{46}$ Em outras palavras, a Literatura Comparada se vale de um procedimento crítico que não ignora a pluralidade da realidade, sua teia de significações, seu rizoma, como diria G. Deleuze, instaurando um espaço de troca.

No que se refere aos Estudos Clássicos, a metodologia comparatista ofereceu uma abertura a novas perspectivas sobre as relações literárias e culturais entre os povos antigos do Mediterrâneo, permitindo uma reavaliação da própria noção que a "tradição" estabeleceu acerca dos gregos, sua literatura e filosofia. Em contrapartida, a Literatura Comparada reafirma a importância de ampliarmos nossas perspectivas metodológicas face a nosso novo contexto, como bem sintetiza Carvalhal: ${ }^{47}$

Se à época de seu surgimento, no século XIX, a Literatura Comparada punha em relação duas literaturas diferentes ou perseguia a migração de um elemento literário de um campo literário a outro, atravessando as fronteiras nacionais, hoje é possível dizer que a atuação se ampliou largamente. Essa ampliação, que corresponde a mudança de paradigmas e que provocou diversas alterações metodológicas na disciplina, constitui a própria história do comparativismo literário. De sua fase inicial, em que era concebida como subsidiária da historiografia literária, passa a exercer outras funções, mais adequadas a outros tempos. Surgida de uma necessidade de evitar o fechamento em si das nações recém constituídas e com uma intenção de cosmopolitismo literário, a Literatura Comparada deixa de exercer essa função "internacionalista" para converter-se em uma disciplina que põe em relação diferentes campos das Ciências Humanas.

Quanto ao problema do "milagre grego", visto por essa perspectiva, ele permite reavaliar o papel dos gregos na história da tradição filosófica e literária ocidental, norteados não por uma ideia de "originalidade", mas de "transculturação", "intertextualidade" e "comparação", apontando para um hibridismo cultural entre "Ocidente" e "Oriente" muito maior do que se podia acreditar no século XIX.

Em resumo, depois de ter caracterizado minimamente o contexto espiritual e histórico da passagem do século XIX para o XX e de ter apresentado uma espécie de genealogia dos Estudos Literários, ressaltando dois de seus eixos interpretativos, a Literatura Comparada e os Estudos Clássicos, buscou-se investigar as relações entre o conceito de "tradição" e o problema do "milagre grego". Assim, o resultado mostrou-se

\footnotetext{
${ }^{46}$ Cf. de Souza; Miranda, op. cit., p. 46-47.

${ }^{47}$ Cf. Carvalhal, op. cit., 1991, p. 9.
} 


\section{nuntius antiquus}

relevante tanto para a Literatura Comparada, quanto para os Estudos Clássicos, uma vez que experimenta a abertura de um diálogo simbiótico entre diferentes campos dos estudos literários, inserindo-se num quadro mais abrangente das discussões metodológicas sobre a interdisciplinaridade. Ao apontar para a superação da aporia do "milagre grego", por meio da metodologia interdisciplinar comparatista, tornou-se possível reconduzir a concepção de "tradição", formulada não mais a partir de modelos absolutos, herdados de véspera, mas através do diálogo interdisciplinar das perspectivas comparatistas, sensíveis à multiciplicidade de vozes da cultura e mais atentas quanto ao estabelecimento de suas fronteiras, uma vez que priorizam as "relações" entre os diferentes, mais do que a submissão de todos a um único padrão.

\section{Referências}

ACHUGAR, H. Weltliteratur ou cosmopolitismo, globalização, "literatura mundial" e outras metáforas problemáticas. In: (org.) Planetas sem boca, escritos efêmeros sobre arte, cultura e literatura. Tradução de Lyslei Nascimento. Belo Horizonte: UFMG, 2006, p. 65-80.

ADORNO, T. W.; HORKHEIMER, M. A indústria cultural: o esclarecimento como mistificação das massas. In: . (org.) Dialética do esclarecimento. Tradução de Guido A. de Almeida. Rio de Janeiro: Zahar, 1985, p. 99-138.

ADRADOS, F. R. La composición de los poemas hesiódicos. Emérita. Madrid, tomo LXIX, n. 2, p. 197-223, 2001.

. Las fuentes de Hesíodo y la composición de sus poemas. Emérita. Madrid, tomo LIV, p. 1-36, 1986.

Sobre los géneros literários en la literatura griega. 1616. Madrid, p. 159-

$172,1978$.

ANÓNIMO. Textos literarios hetitas. Traducción, introducción e notas de A. Bernabe. Madrid: Editora Nacional, 1979.

BORNHEIM, G. A. O conceito de tradição. In: (org.) Cultura brasileira.

Tradição, contradição. Rio de Janeiro: Zahar, 1987, p.15-29.

BOSI, A. Cultura como tradição. In: BORNHEIM, G. A. (org.). Cultura brasileira. Tradição, contradição. Rio de Janeiro: Zahar, 1987, p. 31-58.

BOTTERO, J. Cultura, pensamento e escrita. In: BOTTERO et alii (org.). Tradução de Rosa Maria Boaventura e Valter Lellis Siqueira. São Paulo: Ática, 1995.

. La religion babyloniènne. Paris: Presses Universitaires de France, 1952. 
BRUNEL, P; PICHOIS, C.; ROUSSEAU, A. M. Que é Literatura Comparada? Tradução de Célia Berrettini. São Paulo: Perspectiva, 1995.

BURNET, J. A aurora da filosofia grega. Tradução de Vera Ribeiro. Rio de Janeiro: PUC-RIO, 2006.

CARVALHAL, T. F. Literatura Comparada: a estratégia interdisciplinar. Revista brasileira de Literatura Comparada. Niterói, n. 1, p. 9-21, 1991.

. Literatura Comparada. São Paulo: Ática, 2006.

CHAMBRY, E. Notice sur Ésope. In: ÉSOPE. Fables. Paris: Les Belles Lettres, 1985, p. IX-XXVII.

CORNFORD, F.-M. Principium Sapientiae: as origens do pensamento filosófico grego. Tradução de Maria Manuela R. dos Santos. Lisboa: Calouste Gulbenkian, 1975.

DELEUZE, G. Nietzsche e a filosofia. Tradução de Edmundo Fernandes Dias e Ruth J. Dias. Rio de Janeiro: Ed. Rio, 1976.

. Nietzsche. Tradução de Alberto Campos. Lisboa: Edições 70, 1994.

FOUCAULT, M. A verdade e as formas jurídicas. Tradução de Roberto C. de Melo Machado e Eduardo J. de Moraes. Rio de Janeiro: PUC-RS, 2001.

GERNET, L. Les origines de la philosophie. In. Anthropologie de la Grèce antique. Paris: Flammarion, 2002.

GIBBON, E. Declínio e queda do Império Romano. Tradução de José Paulo Paes. São Paulo: Companhia das Letras, 2005.

GUYARD, M. F. Objeto e método da Literatura Comparada. In: COUTINHO, E. F.; CARVALHAL, T. F. (org.). Literatura comparada: textos fundadores. Rio de Janeiro: Rocco, 1994, p. 97-107.

HARTOG, F. Memória de Ulisses: narrativas sobre a fronteira na Grécia antiga. Tradução de Jacyntho Lins Brandão. Belo Horizonte: UFMG, 2004.

HALL, S. A identidade cultural na Pós-Modernidade. Tradução de Tomaz T. da Silva e Guacira L. Louro. Rio de Janeiro: DP\&A, 1998.

LAMBERT, W. G. Babylonian wisdom literature. Oxford: Clarendon Press, 1960.

KANT, I. Resposta à pergunta: que é "esclarecimento"? In: ___ Textos seletos. Tradução de Floriano S. Fernandes. Petrópolis: Vozes, 1974, p. 100-117.

LESKY, A. História da literatura grega. Tradução de Manuel Losa. Lisboa: Calouste Gulbenkian, 1995. 
MIGNOLO, W. Histórias locais/ projetos globais; colonialidade, saberes subalternos e pensamento liminar. Belo Horizonte: UFMG, 2003, p. 133-180.

MOMigliano, A. Os limites da helenização. Tradução de Cláudia Martinelli Gama. Rio de Janeiro: Zahar, 1991.

NIETZSCHE, F. W. Obras incompletas. Tradução de Rubens Rodrigues Torres Filho. São Paulo: Abril Cultural, 1978.

Humano, demasiado humano. Tradução de Paulo César de Souza. São Paulo: Companhia das Letras, 2005.

. Genealogia da Moral. Tradução de Paulo César de Souza. São Paulo: Companhia das Letras, 1998.

PESSANHA, J. A. M. Cultura como ruptura. In: BORNHEIM, G. (org.). Cultura brasileira. Tradição, contradição. Rio de Janeiro: Zahar, 1987, p. 59-89.

PIGLIA, R. Memoria y Tradición. In: Anais $2^{\circ}$. Congresso Abralic: literatura e memória cultural. Belo Horizonte: 1961, p. 60-66.

RIGHI, G. Historia de la filología clásica. Traducción de J. M. García de la Mora. Barcelona: Labor, 1969.

de SOUZA, E. M.; MIRANDA, W. M. Perspectivas da Literatura Comparada no Brasil. In: CARVALHAL, T. F. (org.). Literatura Comparada no mundo: questões e métodos. Porto Alegre: L \& PM/ VITAE/ AILC, 1997, p. 39-52.

SVEMBRO, J. Hésiode: La vérité comme relation sociale. In: (org.) $L a$ parole et le marbre. Aux origines de la poétique grecque. Lund: Studentlitteratur, 1976, p. 46-73.

VERNANT, J.-P. As origens do pensamento grego. Tradução de Ísis B. B. da Fonseca. Rio de Janeiro: Bertrand Brasil, 1998.

WALCOT, P. Hesiod and the near east. Cardiff: University of Wales Press, 1966.

WARREN, A; WELLEK, R. Literatura Geral, literatura comparada e literatura nacional. In: (org.) Teoria da literatura e metodologia dos estudos literários. Tradução de Luis C. Borges. São Paulo: Martins Fontes, 2003, p. 46-57.

WELLEK, R. A crise da Literatura Comparada. In: COUTINHO, E. F.; CARVALHAL, T. F. Literatura Comparada: textos fundadores. Tradução de Maria L. R. Coutinho. Rio de Janeiro: Rocco, 1994, p. 108-119.

WEST, M. L. The east face of Helicon: west Asiatic elements in Greek poetry and myth. Oxford/ New York: Clarendon Press, 1997. 